\title{
Deep mitochondrial introgression and hybridization among ecologically divergent vole species
}

\author{
CRISTIANE BASTOS-SILVEIRA, ${ }^{*}+$ SARA M. SANTOS, + RITA MONARCA, + MARIA DA LUZ \\ MATHIAS $\uparrow+$ and GERALD HECKEL $\uparrow$ \\ *Museu Nacional de História Natural e da Ciencia, Universidade de Lisboa, Rua da Escola Politécnica, 58, 1269-102, Lisboa, \\ Portugal, †Centre for Environmental and Marine Studies (CESAM), Universidade de Aveiro, 3810-193, Aveiro, Portugal, \\ $\$$ \$Departamento de Biologia Animal, Faculdade de Ciências, Universidade de Lisboa, Campo Grande, 1749-016, Lisbon, Portugal, \\ $\S$ Computational and Molecular Population Genetics (CMPG), Institute of Ecology and Evolution, University of Bern, \\ Baltzerstrasse 6, CH-3012, Bern, Switzerland, -Swiss Institute of Bioinformatics, Genopode, 1015, Lausanne, Switzerland
}

\begin{abstract}
The completion of speciation is typically difficult to ascertain in rapidly diverging taxa but the amount of hybridization and gene flow in sympatry or parapatry contains important information about the level of reproductive isolation achieved. Here, we examined the progress in speciation between the Mediterranean (Microtus duodecimcostatus) and the Lusitanian pine vole (M. lusitanicus), which are part of the most rapid radiation of species known in mammals. These two Iberian pine voles are classified as separate species because of differences in morphology and ecology, but relatively many ambiguous individuals can be found in sympatric conditions. Our phylogenetic analyses of rangewide data from the mitochondrial cytochrome $b$ gene (mtDNA) demonstrated high levels of diversity and a basal separation in two parapatric lineages. However, mtDNA affiliation was at odds with morphological classification or geographical distribution of the taxa. In contrast, statistical analyses of microsatellites (nucDNA) showed two clear genetic clusters in allopatry and sympatry generally matching morphological classification. This cytonuclear discordance over a large geographic area suggests historical introgression of mtDNA from $M$. duodecimcostatus to M. lusitanicus. There was statistical evidence for at least two recent hybrids in the sympatry zone but gene flow is apparently low given clear-cut differences in nucDNA. Our results indicate a relatively advanced speciation process in these Iberian pine voles without fully established reproductive isolation. This situation enables use of combined population genomic and experimental approaches for the separation of patterns and mechanisms in the ongoing explosive diversification of these and other Arvicoline rodents in the future.
\end{abstract}

Keywords: Iberian Peninsula, introgression, microsatellites, Microtus, mitochondrial DNA, speciation

Received 10 April 2012; revision received 27 July 2012; accepted 30 July 2012

\section{Introduction}

Speciation requires the termination of gene flow between taxa. This is less likely to occur in sympatric or parapatric conditions with ample opportunity for interbreeding than in situations where populations are

Correspondence: Cristiane Bastos-Silveira, Fax:+351213969784; E-mail: cbsilveira@fc.ul.pt separated in allopatric distribution ranges and reproductive isolation may evolve over time (Mallet et al. 2009; Petit \& Excoffier 2009; Smadja \& Butlin 2011). The secondary contact of such populations or taxa is a decisive step in which the progress of the speciation process is tested, and where (experimental) hybridization may provide means to determine the relative importance of differences in ecological, genetic, or phenotypic traits between taxa for reproductive isolation (Coyne \& Orr 
2004; Nosil et al. 2009; Maan \& Seehausen 2011). However, divergence among nascent species is rarely consistent across different traits or parts of their genomes, and thus the position of recently diverged taxa in the speciation process is often difficult to assess (Petit \& Excoffier 2009; Smadja \& Butlin 2011; Beysard et al. 2012).

The genus Microtus represents probably the most rapid mammalian radiation resulting in more than 65 extant species over the course of only 1.2-2 Myr (Jaarola et al. 2004; Fink et al. 2010). Taxonomic classifications are particularly difficult in the genus owing to the speed of the Microtus radiation and often gradual variation in morphological and molecular traits between extant taxa (Mitchell-Jones et al. 1999). A recent molecular analysis of the radiation demonstrated the importance of geographic isolation in the genus with subradiations in North America, Asia and Europe and secondary colonization (Fink et al. 2010). Phylogeographical analyses have provided evidence of relatively deep divergence between parapatric evolutionary lineages within recognized species (Jaarola \& Searle 2002; Brunhoff et al. 2003; Fink et al. 2004; Heckel et al. 2005). However, the taxonomic status of these lineages is often unclear and some may represent unrecognized species (e.g. Microtus agrestis: Hellborg et al. 2005; Beysard et al. 2012; M. arvalis: Heckel et al. 2005; Braaker \& Heckel 2009).

The Mediterranean pine vole (M. duodecimcostatus, De Selys-Longchamps 1839) and the Lusitanian pine vole (M. lusitanicus, Gerbe 1879) are typically classified as separate species (Mitchell-Jones et al. 1999). Morphological discrimination is mainly based on the larger size and weight of M. duodecimcostatus (e.g. Cabrera 1914;
Ellerman \& Morrison-Scott 1951) but craniometrical analyses allow the identification of the taxa based on skulls and mandibles alone (Madureira 1981). These pine voles differ also in a range of ecological characters, such as the type of inhabited soils and their commitment to a life underground. The Lusitanian pine vole occurs in regions dominated by fertile, well-drained and easily mobilized soils (cambisols), and colder and moister climate compared with the Mediterranean pine vole, which occupies mainly grassland landscapes with higher abundance of stony soils (leptosols) and clayey soils with lower acidity (luvisols; Santos et al. 2009, 2010a). Both voles occupy preferentially open habitats, which may be agriculturally influenced (Cotilla \& Palomo 2002; Mira \& Mathias 2002), typically in close association with verges (Santos et al. 2011). They feed on roots, tubers, fruits and other parts of plants (Cotilla \& Palomo 2002; Mira \& Mathias 2002), but there are no data regarding differences in diet between these two species. The mating systems of the two taxa have not been studied in detail but limited data indicated social monogamy for M. duodecimcostatus (Paradis \& Guédon 1993; Santos et al. 2010b) while Microtus species like most mammals are generally rather promiscuous or polygynous (Fink et al. 2006, 2007).

The distribution ranges are largely allopatric with M. duodecimcostatus in the southern-central Iberian Peninsula and southern France and M. lusitanicus in the north of Iberia including the French Pyrenees, but there is an extensive area of sympatry in parts of Portugal and Spain (Madureira 1984; Mitchell-Jones et al. 1999; Cotilla \& Palomo 2002; Mira \& Mathias 2002; Fig. 1). There is no information regarding natural hybridization

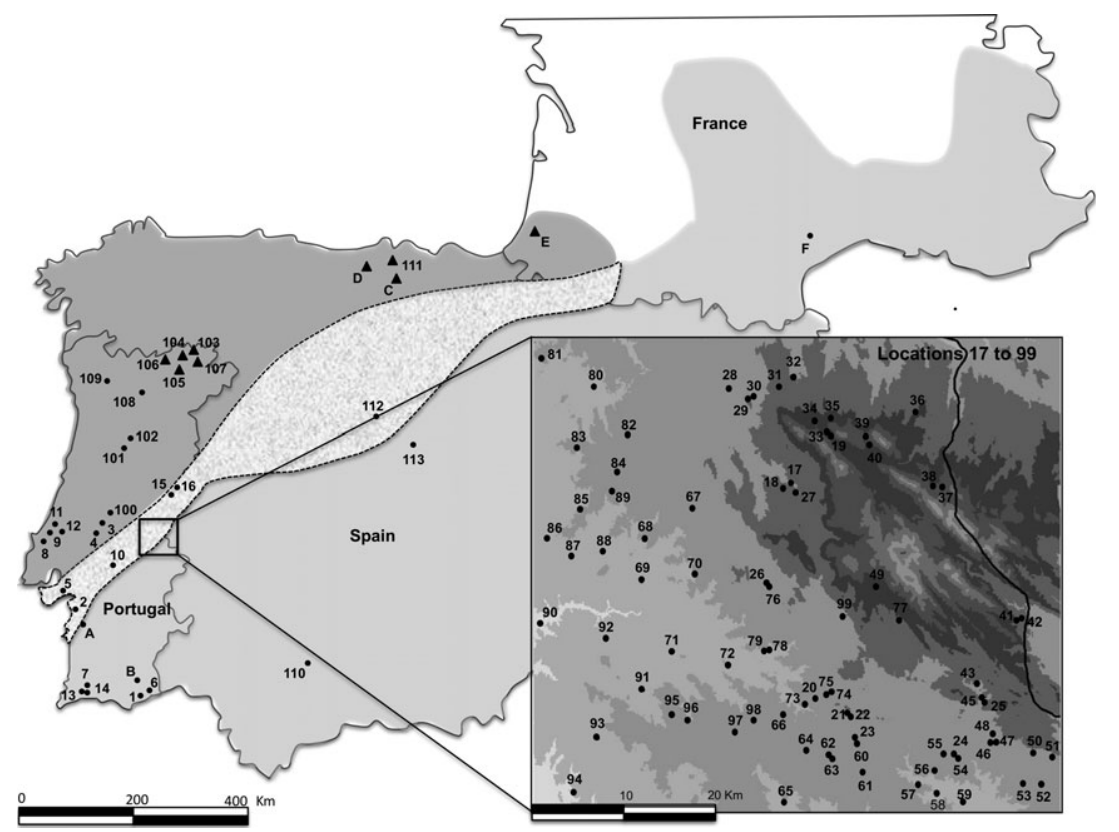

Fig. 1 Map of the ranges of the southwestern European endemic rodents Microtus lusitanicus (dark grey shading) and M. duodecimcostatus (light grey shading). The area of sympatric occurrence according to morphological data is delimited by the dashed lines. Dots and triangles indicate the sampling sites for mitochondrial and nuclear analyses of the present study, which are cross-referenced with Table 1. Capital letters indicate the geographical origin of $c y t b$ sequences from GenBank: M. lusitanicus from France (E) and Spain (C, D), and M. duodecimcostatus from France (F) and Portugal (A, B). Black triangles indicate sampling sites with M. lusitanicus mtDNA haplotypes; dots those with $M$. duodecimcostatus mtDNA. 
between these two taxa, but it is possible to cross them under laboratory conditions (Wiking 1976).

Phylogenetic analyses of the Microtus genus based on the mitochondrial cytochrome $b$ gene revealed $4-5 \%$ sequence divergence between $M$.duodecimcostatus and M. lusitanicus individuals sampled in the allopatric parts of the distribution ranges (Jaarola et al. 2004; see Fig. 1). This divergence is at the lower end of the values between recognized Microtus species and at the upper end of the divergence between allopatric lineages within some other species (e.g. Fink et al. 2004; Jaarola et al. 2004). Phylogeographic analyses of M. duodecimcostatus and M. lusitanicus are lacking, and without data from the area of sympatry it is impossible to distinguish whether genetic divergence between the two taxa is only owing to the potential effect of isolation by distance between allopatric genetic lineages within a species (see e.g. Heckel et al. 2005) or owing to evolutionary divergence between reproductively isolated species.

'Molecular taxonomy' based on a single genetic marker like mitochondrial DNA (mtDNA) may be misleading or remain inconclusive because of a markerspecific evolutionary history (Ballard \& Whitlock 2004) or because taxa continue to exchange genes or share polymorphisms predating their separation (Petit \& Excoffier 2009). Thus, in a scenario of low divergence and potential hybridization such as in Iberian Microtus, only the combined analysis of molecular markers with different speed of evolution and different modes of inheritance may be powerful enough to characterize the extent of overall divergence between taxa, detect historical and recent hybridization, and reveal the direction of introgression (e.g. Berthier et al. 2006; Good et al. 2008; Renoult et al. 2009). The aims of the present study were thus (i) to assess the extent of genetic divergence between the two pine vole taxa in both the allopatric and sympatric areas of the distribution ranges; (ii) to examine the concordance between species delimitations based on morphology, mitochondrial and nuclear DNA; and (iii) to test for evidence of hybridization between the morphologically defined and ecologically divergent taxa in the area of sympatry.

\section{Material and methods}

\section{Samples and DNA extraction}

The present study is based on 296 samples from 113 locations spanning almost the entire distribution ranges of M. duodecimcostatus and M. lusitanicus in south-western Europe with a particular focus on the area of sympatry (Portalegre district, Portugal; Fig. 1; Table 1). Most of the samples $(N=283)$ came from animals that were captured using subterranean live traps of multiple captures ('mole type'). Global positioning system (GPS) was used to register capture locations. Tissue samples (tail; muscle from dead animals) were stored in absolute ethanol at $-20{ }^{\circ} \mathrm{C}$.

Species identification of the live-trapped animals in the field was based on morphological characteristics: hind feet length (M. lusitanicus $<16 \mathrm{~mm} ; M$. duodecimcostatus $>16 \mathrm{~mm}$ ) and body length (M. lusitanicus $<105 \mathrm{~mm}$ and $M$. duodecimcostatus $>89 \mathrm{~mm}$ ). Coat colour patterns were additionally used for classification of 16 of 197 voles from the sympatric area presenting feet and body length in the overlapping range (Madureira 1984). Individuals were further classified as adult or subadult/juvenile based on external signs of reproductive activity (testes visible, pregnancy or lactation signs). Based on these morphological traits, our data set included fresh samples from 127 M. duodecimcostatus (including 49 adults), 104 M. lusitanicus (30 adults) and 52 (33 adults) further individuals for which assignment to either species based on morphology was difficult (hereafter termed Microtus sp). Thirteen additional samples came from the Tissue and DNA Collection of the Museu Nacional de História Natural e da Ciência (MB), Portugal, the Museo Nacional de Ciencias Naturales (MNCN), Spain, and one dry skin from the vertebrate collection of the Estación Biológica Doñana (EBD), Spain. Genomic DNA was extracted using standard protocols requiring incubation with SDS and digestion with proteinase $\mathrm{K}$, followed by a phenol-chloroform DNA extraction (Sambrook et al. 1989).

\section{DNA sequencing}

The complete mitochondrial cytochrome $b$ (cytb) gene (1140 bp) was amplified and sequenced using Microtus specific primers L14727-SP and H-15195-SP (Jaarola \& Searle 2002). All reactions contained $100 \mathrm{ng}$ of template DNA, $0.3 \mathrm{~mm}$ of each primer, $1 \mathrm{U}$ of Taq DNA Polymerase, $1 \times$ buffer, $2.5 \mathrm{~mm} \mathrm{MgCl}_{2}$ and $0.2 \mathrm{~mm}$ of each dNTP to a final volume of $25 \mu \mathrm{L}$. DNA amplifications were performed using the following conditions: denaturation at $95{ }^{\circ} \mathrm{C}$ for $5 \mathrm{~min}$, followed by 40 cycles of denaturation at $94{ }^{\circ} \mathrm{C}$ for $1 \mathrm{~min}$, annealing at $50{ }^{\circ} \mathrm{C}$ for $1 \mathrm{~min}$ and extension at $72{ }^{\circ} \mathrm{C}$ for $1 \mathrm{~min}$. An extension step at $72{ }^{\circ} \mathrm{C}$ for $10 \mathrm{~min}$ was added at the end. We purified PCR products and directly sequenced on an ABI 3100 Genetic Analyzer (Applied Biosystems, USA).

\section{Sequence analysis}

The $c y t b$ sequences were aligned and translated into amino acids using Sequencher ${ }^{\mathrm{TM}}$ 4.8. To ensure the mitochondrial origin of the sequences, they were checked for the presence of stop codons and compared against GenBank entries of M. duodecimcostatus and M. lusitanicus. 
Table 1 Sampling sites (country, location and coordinates) of Microtus sp (M), M. lusitanicus (ML) and M. duodecimcostatus (MD) used for this study. Map reference numbers are listed as displayed in Fig. 1 and samples locations within the sympatric area are marked with $x$. Given are numbers of samples analysed for microsatellites and $c y t b$, and $c y t b$ haplotypes

\begin{tabular}{|c|c|c|c|c|c|c|c|c|}
\hline Map ref. & Location & UTMx & UTMy & MorphoID & Microsat & Cyt $b$ & Cyt $b$ haplotypes & Accession numbers \\
\hline \multicolumn{9}{|l|}{ Portugal } \\
\hline 1 & Monte Gordo* & 608312 & 4407400 & MD & 2 & - & - & \\
\hline 2 & Setubal ${ }^{*}$ & 475998 & 4316844 & MD & 1 & - & - & \\
\hline 3 & Almerin* & 531953 & 4340281 & ML & 1 & - & - & \\
\hline 4 & Boquilobo* & 540084 & 4359595 & ML & 2 & - & - & \\
\hline 5 & Pancas* & 475998 & 4316844 & ML & 1 & - & - & \\
\hline 6 & Castro Marin* & 637945 & 4120515 & MD & 1 & - & - & \\
\hline 7 & Silves & 549722 & 4116257 & MD & 1 & - & - & \\
\hline 8 & Obidos & 483192 & 4355308 & ML & 2 & 1 & R0QP & JX424119 \\
\hline 9 & Caldas & 490897 & 4364192 & ML & 2 & 1 & R0SJ & JX424120 \\
\hline 10 & Cabeção & 578654 & 4313479 & $\mathrm{M}$ & 3 & 1 & ID006 & JX424121 \\
\hline 11 & Alcobaça & 503321 & 4377793 & ML & 1 & 1 & ID010 & JX424122 \\
\hline 12 & Candeeiros & 506672 & 4364861 & ML & 1 & 1 & ID011 & JX424123 \\
\hline 13 & Porto Lagos & 541831 & 4116913 & MD & 7 & 3 & ID015.1, ID015.2 & JX424124-125 \\
\hline 14 & Pomar jovem & 540453 & 4120826 & $\mathrm{MD}$ & 6 & 2 & ID016.1, ID016.2 & JX424126-127 \\
\hline 15 & Medelim & 656188 & 4432895 & MD & 5 & 4 & $\begin{array}{l}\text { ID018.1, ID018.2, } \\
\text { ID018.3 }\end{array}$ & $\begin{array}{l}\text { JX424128-129 } \\
\text { JX424130 }\end{array}$ \\
\hline 16 & Medelim & 653227 & 4429596 & $\mathrm{M}$ & 1 & 2 & ID019.1, ID019.2 & JX424131 \\
\hline $17(\mathrm{x})$ & Rib Nisa & 632170 & 4358562 & ML & 2 & 1 & ID025 & JX424133 \\
\hline $18(x)$ & Matinha & 631490 & 4358186 & ML & 5 & 2 & ID026 & JX424134 \\
\hline $19(x)$ & Barretos & 635141 & 4362647 & ML & 3 & 1 & ID027 & JX424135 \\
\hline $20(x)$ & Microcolonia & 634379 & 4340922 & MD & 2 & 1 & ID030 & JX424136 \\
\hline $21(\mathrm{x})$ & Vacas & 635287 & 4341222 & MD & 3 & 1 & ID031 & JX424137 \\
\hline $22(x)$ & Ilha & 637362 & 4339325 & MD & 1 & - & - & \\
\hline $23(x)$ & Plantação sobreiro & 637817 & 4337196 & MD & 7 & 1 & ID034 & JX424138 \\
\hline $24(\mathrm{x})$ & Mosteiros & 646355 & 4336018 & MD & 2 & 1 & ID035 & JX424139 \\
\hline $25(x)$ & Barulho/Besteiros & 648442 & 4340706 & ML & 1 & 1 & ID036 & $\mathrm{JX} 424140$ \\
\hline $26(x)$ & Subestação EDP & 630222 & 4350230 & MD & 4 & 3 & ID038.1, ID038.2 & JX424141-142 \\
\hline $27(\mathrm{x})$ & Castanheira & 632629 & 4357811 & ML & 2 & 1 & R032 & JX424143 \\
\hline $28(x)$ & Pegos Dobrados & 626910 & 4366208 & ML & 2 & 1 & R041 & JX424144 \\
\hline $29(x)$ & Lavradores I & 628547 & 4365368 & $\mathrm{M}$ & 2 & 1 & R042 & JX424145 \\
\hline $30(x)$ & Lavradores II & 628984 & 4365546 & $\mathrm{M}$ & 1 & 1 & R041 & JX424144 \\
\hline $31(x)$ & Tinhosa & 631137 & 4366362 & ML & 3 & 2 & ID027, R044 & JX424135-146 \\
\hline $32(x)$ & Canto das Nogueiras & 632242 & 4367129 & ML & 1 & 1 & $\mathrm{R} 045$ & JX424147 \\
\hline $33(x)$ & Est Vale Rodao I & 634160 & 4363570 & ML & 3 & 1 & ID027 & JX424135 \\
\hline $34(\mathrm{x})$ & Est Vale Rodao II & 634134 & 4363581 & ML & 2 & 2 & ID036, R049 & JX424140-148 \\
\hline $35(x)$ & Amieira & 635370 & 4363765 & ML & 2 & 1 & R052 & JX424149 \\
\hline $36(x)$ & St. Ant. Areias & 642471 & 4364401 & ML & 4 & 1 & R045, R057 & JX424147-150 \\
\hline $37(\mathrm{x})$ & Penha Esparoeira & 644781 & 4358273 & ML & 5 & 1 & R059 & JX424151 \\
\hline $38(x)$ & Braçais & 644077 & 4358333 & ML & 1 & 1 & R062 & JX424152 \\
\hline $39(x)$ & Marvão & 638378 & 4362395 & ML & 2 & 1 & R049 & JX424148 \\
\hline $40(x)$ & Marvão/Jardim & 638717 & 4361656 & ML & 6 & 1 & R065 & JX424153 \\
\hline $41(\mathrm{x})$ & Rabaça I & 651434 & 4347527 & ML & 1 & 1 & $\mathrm{R} 070$ & JX424154 \\
\hline $42(\mathrm{x})$ & Rabaça II & 651510 & 4347570 & ML & 2 & 2 & R071.1, R071.2 & JX424155-156 \\
\hline $43(x)$ & Vale das Púdicas I & 647818 & 4342220 & $\mathrm{M}$ & 3 & 2 & $\mathrm{R} 075$ & JX424157 \\
\hline $44(\mathrm{x})$ & Vale das Púdicas Ia & 647825 & 4342196 & ML & 2 & 2 & R044, R075 & JX424146-157 \\
\hline $45(\mathrm{x})$ & Vale das Púdicas II & 647794 & 4342125 & $\mathrm{M}$ & 4 & - & - & \\
\hline $46(x)$ & Monte dos Moços I & 649345 & 4337370 & MD & 1 & 1 & R082 & JX424158 \\
\hline $47(\mathrm{x})$ & Monte dos Moços II & 649375 & 4337423 & MD & 1 & 1 & R082 & JX424158 \\
\hline $48(\mathrm{x})$ & Azenha nova & 648395 & 4340704 & ML & 3 & 3 & ID036, R082, R085 & JX424140-158-159 \\
\hline $49(\mathrm{x})$ & Reguengo & 639362 & 4350070 & $\mathrm{ML}$ & 4 & 3 & R045, R071.1 & JX424147-155 \\
\hline $50(x)$ & Serrinha & 654187 & 4336171 & MD & 1 & 1 & ID034 & JX424138 \\
\hline $51(\mathrm{x})$ & Nave fria & 652562 & 4336594 & ML & 5 & 1 & R086 & JX424160 \\
\hline $52(x)$ & Figueira & 653245 & 4333969 & MD & 5 & 5 & R092 & JX424161 \\
\hline $53(x)$ & Martin Tavares & 651812 & 4334034 & MD & 2 & 1 & ID035 & JX424139 \\
\hline
\end{tabular}


Table 1 Continued

\begin{tabular}{|c|c|c|c|c|c|c|c|c|}
\hline Map ref. & Location & UTMx & UTMy & MorphoID & Microsat & Cyt $b$ & Cyt $b$ haplotypes & Accession numbers \\
\hline $54(\mathrm{x})$ & Ronseiras & 646028 & 4336337 & MD & 2 & 2 & R094.1, R094.2 & JX424162-163 \\
\hline $55(x)$ & Algeireirinhas & 645053 & 4336337 & MD & 3 & 1 & R095 & JX424164 \\
\hline $56(x)$ & Freirinha & 644428 & 4334998 & MD & 2 & - & - & \\
\hline $57(x)$ & Monte Faia & 643064 & 4333813 & MD & 2 & 1 & R097 & JX424165 \\
\hline $58(x)$ & Fragosa & 644564 & 4333044 & MD & 3 & 1 & R098 & JX424166 \\
\hline $59(x)$ & Arronches & 646723 & 4332355 & MD & 1 & 1 & - & \\
\hline $60(x)$ & Monte Ferrador & 637684 & 4337575 & MD & 3 & 1 & R100 & JX424167 \\
\hline $61(x)$ & Assmar & 638395 & 4334883 & MD & 2 & 2 & R101.1, R101.2 & JX424168-169 \\
\hline $62(x)$ & Monte Alcaide I & 635566 & 4336187 & MD & 2 & 1 & R102 & JX424170 \\
\hline $63(x)$ & Monte Alcaide II & 635514 & 4336204 & MD & 4 & 1 & R103 & JX424171 \\
\hline $64(x)$ & Escudeiros & 633684 & 4336569 & MD & 2 & 1 & R104 & JX424172 \\
\hline $65(x)$ & Monte Évora & 631843 & 4332291 & MD & 4 & 1 & R105 & JX424173 \\
\hline $66(x)$ & Sobreiral & 631756 & 4339455 & MD & 4 & 1 & R106 & JX424174 \\
\hline $67(x)$ & Cerejeira-Alagoa & 623986 & 4356367 & ML & 11 & 1 & R114 & JX424175 \\
\hline $68(x)$ & Monte Alegre & 620029 & 4353824 & MD & 1 & - & - & \\
\hline $69(x)$ & Monte Romeiras & 619762 & 4350322 & ML & 1 & - & - & \\
\hline $70(x)$ & Sra Martires & 624167 & 4351032 & MD & 1 & 1 & R118 & JX424176 \\
\hline $71(\mathrm{x})$ & Abodaneira & 622447 & 4344566 & MD & 2 & - & R120 & JX424177 \\
\hline $72(x)$ & Cabeco Malhadio & 627075 & 4343453 & MD & 2 & 1 & $\mathrm{R} 121$ & JX424178 \\
\hline $73(x)$ & Inglesinha & 633496 & 4340295 & MD & 7 & 2 & R082, R122 & JX424158-179 \\
\hline $74(x)$ & Monte Bonito I & 635633 & 4341489 & $\mathrm{M}$ & 4 & 1 & R041 & JX424144 \\
\hline $75(x)$ & Monte Bonito II & 635598 & 4341478 & M & 5 & 1 & R045 & JX424147 \\
\hline $76(x)$ & Subestacao EDP & 630226 & 4350175 & M & 4 & - & R125 & JX424180 \\
\hline $77(\mathrm{x})$ & Penha hortas & 641233 & 4347376 & ML & 1 & 1 & R071.1 & JX424155 \\
\hline $78(\mathrm{x})$ & Entreribeiras I & 630014 & 4344679 & MD & 1 & 1 & R128 & JX424181 \\
\hline $79(x)$ & Entreribeiras II & 630001 & 4344689 & $\mathrm{MD}$ & 1 & 1 & R129 & JX424182 \\
\hline $80(x)$ & Pedreira & 615705 & 4366292 & ML & 2 & 1 & R131 & JX424183 \\
\hline $81(\mathrm{x})$ & Miguel Pestana Bastos & 611255 & 4368583 & $\mathrm{M}$ & 3 & 1 & R133 & JX424184 \\
\hline $82(x)$ & Alpalhao & 618518 & 4362286 & M & 1 & - & - & \\
\hline $83(\mathrm{x})$ & Gafete Cortesoes & 614282 & 4361253 & M & 1 & - & - & \\
\hline $84(\mathrm{x})$ & Vale Peso & 617646 & 4359268 & M & 2 & - & - & \\
\hline $85(x)$ & Campainhas & 614628 & 4356117 & M & 2 & 1 & R137 & JX424185 \\
\hline $86(x)$ & Atalainha & 611880 & 4353774 & M & 4 & 1 & R138 & JX424186 \\
\hline $87(\mathrm{x})$ & Ponte velha & 613934 & 4352313 & M & 3 & 1 & R139 & JX424187 \\
\hline $88(x)$ & Flor Rosa & 616555 & 4352673 & M & 1 & 1 & R141 & JX424188 \\
\hline $89(x)$ & Vale Vaqueiros & 617312 & 4357663 & M & 4 & 1 & $\mathrm{R} 142$ & JX424189 \\
\hline $90(x)$ & Ponte Rib Seda & 611417 & 4346845 & $\mathrm{M}$ & 1 & 1 & R143 & JX424190 \\
\hline $91(x)$ & Coutada Pina & 619989 & 4341421 & MD & 1 & 1 & R147 & JX424191 \\
\hline $92(x)$ & Rib Linhais & 616839 & 4345535 & MD & 5 & - & - & \\
\hline $93(x)$ & Outeiro Ferreiros & 616223 & 4337419 & MD & 3 & 1 & R151 & JX424192 \\
\hline $94(\mathrm{x})$ & Monte Marinheira & 614359 & 4332957 & $\mathrm{MD}$ & 2 & 1 & R153 & JX424193 \\
\hline $95(x)$ & Silveira I & 622389 & 4339454 & MD & 6 & 1 & R160 & JX424194 \\
\hline $96(x)$ & Silveira II & 623698 & 4338902 & MD & 7 & 1 & R161 & JX424195 \\
\hline $97(\mathrm{x})$ & Ribeiro Freixo & 627679 & 4338033 & MD & 1 & 1 & R162 & JX424196 \\
\hline $98(x)$ & Cabeca Alta & 629341 & 4338957 & MD & 1 & 1 & R163 & JX424197 \\
\hline $99(x)$ & Portalegre & 636696 & 4347623 & ML & 2 & 1 & $\mathrm{R} 167$ & JX424198 \\
\hline 100 & Tomar & 559328 & 4387052 & ML & 15 & 3 & R200.1, R200.2 & JX424199-200 \\
\hline 101 & Senhorim & 598925 & 4488440 & ML & 1 & - & - & \\
\hline 102 & Germil & 606428 & 4499718 & ML & 2 & 1 & Ri050 & JX424201 \\
\hline 103 & Nogueira & 681967 & 4625688 & ML & 1 & 1 & RI052 & JX424202 \\
\hline 104 & Santuario & 678155 & 4624532 & ML & 1 & 1 & Ri053 & JX424203 \\
\hline 105 & Ervedosa & 662054 & 4617841 & ML & 3 & 3 & $\begin{array}{l}\text { Ri057.1, Ri057.2, } \\
\text { Ri057.3 }\end{array}$ & $\begin{array}{l}\text { JX424204-205 } \\
\text { JX424206 }\end{array}$ \\
\hline 106 & Rebordelo & 655770 & 4626801 & ML & 1 & 1 & Ri058 & JX424207 \\
\hline 107 & Grijo da Parada & 690830 & 4620892 & ML & 1 & 1 & Ri060 & JX424208 \\
\hline 108 & Alijó & 627718 & 4574842 & ML & 1 & 1 & Ri064 & JX424209 \\
\hline 109 & Rio Longo & 570953 & 4605326 & ML & 1 & 1 & Ri075 & JX424210 \\
\hline
\end{tabular}


Table 1 Continued

\begin{tabular}{|c|c|c|c|c|c|c|c|c|}
\hline Map ref. & Location & UTMx & UTMy & MorphoID & Microsat & Cytb & Cyt $b$ haplotypes & Accession numbers \\
\hline \multicolumn{9}{|l|}{ Spain } \\
\hline 110 & Cordoba* & 343687 & 4193264 & MD & 1 & - & - & \\
\hline 111 & Ventorrillo* & 411890 & 4769087 & $\mathrm{M}$ & 1 & - & - & \\
\hline 112 & Segovia† & 404784 & 4532876 & MD & 1 & 1 & DS3 & JX424211 \\
\hline 113 & Madrid $\dagger$ & 441665 & 4470636 & MD & 1 & 1 & DS3 & JX424211 \\
\hline Total & & & & & 295 & 122 & 93 & \\
\hline
\end{tabular}

*Samples from MNHNC-Portugal.

$†$ Samples from Museo Nacional de Ciencias Naturales-Spain.

Six additional $c y t b$ sequences, from specimens captured in France (AJ717744 and AJ717746), Spain (AY513812 and AY513813) and Portugal (AY513796 and AY513797), were included in our data set to complement the range-wide coverage of our analyses (see Fig. 1). The identity and frequency of haplotypes in the data set was determined with ARLEQUIN 3.1 (Excoffier et al. 2005). Net average divergence (Da) (Nei \& Li 1979) between mtDNA clusters was estimated using the Tamura-Nei model (Tamura \& Nei 1993) in MEGA 5.05 (Tamura et al. 2011). Standard errors were estimated by the bootstrap method using 10000 replicates. Redundant haplotypes were removed for phylogenetic analyses.

Phylogenetic relationships among $c y t b$ haplotypes were reconstructed analogous to the analyses described in Braaker \& Heckel (2009). Briefly, phylogenetic analyses were performed using the Neighbour-Joining method implemented in MEGA 5.05 (Tamura et al. 2011) and Bayesian algorithms implemented in MRBAYES 3.1.2 (Ronquist \& Huelsenbeck 2003). The closely related species $M$. gerbei (Jaarola et al. 2004) was used as outgroup to root the phylogenetic trees (AY513800). JMODELTEST 0.0.1 (Posada 2008) was used to select the best-fitting model of nucleotide substitution. Different selection criteria (Akaike Information Criterion and Bayesian Information Criterion) identified the same model: the general time-reversible substitution model with a proportion of invariable sites and a gammadistributed rate variation across sites $(G T R+I+G$; Tavaré et al. 1997). The estimated parameters of the model were as follows: substitution rate matrix $[\mathrm{AC}]=1.1368$; $[\mathrm{AG}]=$ 23.9209; $[\mathrm{AT}]=0.4109 ;[\mathrm{CG}]=1.1577 ;[\mathrm{CT}]=9.4057$ and [GT] $=1.0000$; gamma shape parameter $=0.6900$, with $72.8 \%$ of invariable sites; and nucleotide frequencies of $\mathrm{A}=0.3079 ; \mathrm{C}=0.3041 ; \mathrm{G}=0.1311$ and $\mathrm{T}=0.2568$.

The Bayesian analysis was performed three times using the GTR $+\mathrm{I}+\mathrm{G}$ model, each analysis starting from two different random trees for two million generations with every 100th generation sampled. Each run used one cold and three heated chains simultaneously. For each analysis, the average standard deviation of split frequencies at completion between the independent runs was compared with check for convergence on a stationary distribution (Ronquist \& Huelsenbeck 2003). The first $25 \%$ of the trees were discarded as burn-in and the remaining trees were used to reconstruct a consensus and estimate Bayesian posterior probabilities.

\section{Microsatellite genotyping}

Nuclear DNA variability of 295 individuals was assessed by genotyping 13 microsatellite loci: MM1 and MM2 (Ishibashi et al. 1999), CRB5 and CRB7 (Ishibashi et al. 1995), MAG6 and MAG25 (Jaarola et al. 2007), MAR3, 12, 16, 63, 76, 80 and AVP-INb (Walser \& Heckel 2008; Hahne et al. 2011). PCR amplification was performed using the Qiagen Multiplex Kit according to the protocol described in Braaker \& Heckel (2009). Fragment separation was carried out on an $\mathrm{ABI} 3100$ sequencer and the genotypes were scored using GENEMAPPER software 3.7 (Applied Biosystems) against the internal LIZ 500 size standard. Five per cent of the genotypes were independently reamplified and scored to ensure repeatability and quality of genotyping.

\section{Microsatellite analysis}

The software CONVERT 1.2 (Glaubitz 2004) and FORMATOMATIC 0.8.1 (Manoukis 2007) were used to prepare the input files for all software used for microsatellite data analyses. ARLEQUIN 3.1 (Excoffier et al. 2005) was used to calculate general diversity estimates such as the number of alleles per locus, observed $\left(H_{\mathrm{o}}\right)$ and expected heterozygosity $\left(H_{\mathrm{e}}\right)$.

Principal component analysis (PCA), performed in PCAGEN (Goudet 1999), was used as an exploratory method to visualize patterns of multilocus genotypic differentiation among individuals without using information regarding their morphology-based classification as M. duodecimcostatus, M. lusitanicus or M. sp. Further, several Bayesian methods were applied to investigate possible natural hybridization at the Alto Alentejo sympatric area. First, we employed an individual-based 
approach implemented in GENELAND 2.0.12 (Guillot et al. 2005) aiming to determine the number and distribution of genetic clusters present in the sympatric area in consideration of the spatial coordinates where voles were trapped. We inferred the most probable number of genetic clusters $(K)$ in the data set by performing 500000 Markov chain Monte Carlo (MCMC) iterations with a maximum rate of Poisson processes fixed to 200, which is a value close to the number of individuals in our data set, as suggested by Guillot et al. (2005). K was allowed to vary between 1 and 10 , and the uncertainty attached to spatial coordinates was specified as 0.01 . We used 600 as the maximum number of nuclei in the Poisson-Voronoi tessellation (three times the maximum rate of Poisson processes) as suggested by Guillot et al. (2005), and an independent Dirichlet distribution model for allele frequencies. To check the consistency of the results, the MCMC was run 10 times. Once $K$ was determined, we performed a second series of 100 independent runs using the same parameters but $K$ fixed to the value identified in the first step. The average logarithm of the posterior probability was computed for each of the 100 runs, and the 10 runs with the highest mean posterior probability values were kept for inference.

Additionally, we applied two Bayesian methods, which are tailored to identify hybrid individuals but use different approaches. STRUCTURE 2.3.2 (Pritchard et al. 2000) assigns probabilities for individuals to have recent ancestry in two or more populations, while NEWHYBRIDS 1.1 (Anderson \& Thompson 2002) estimates the probability of individuals belonging to distinct hybrid or pure-bred classes.

STRUCTURE was run with ten repetitions of 100000 MCMC iterations following a burn-in period of 20000 steps, the admixture model, correlated allele frequencies and no prior population information. The number of clusters ( $K=1$ to 10$)$ was tested according to Evanno et al. (2005). For the optimal $K$, we assessed the average proportion of membership $\left(Q_{\mathrm{i}}\right)$ of each individual to the inferred clusters and assigned them based on threshold values of the individual membership proportion $\left(q_{\mathrm{i}}\right)$. NEWHYBRIDS computes the posterior probability of a multilocus genotype for being either of pure origin for one of two parental classes or for belonging to one of four potential hybrid classes arising from two generations of interbreeding. For our study, the six classes were pure M. duodecimcostatus, pure M. lusitanicus, F1 hybrid, F2 hybrid, backcross with M. duodecimcostatus and backcross with M. lusitanicus. For the analyses, individuals were not classified a priori by morphological species identification. NEWHYBRIDS was run ten times using the default parameters with a uniform prior for the six classes, a burn-in phase of 10000 steps and 100000 further MCMC sweeps as suggested by the authors. The posterior probability for each individual and the hybrid categories estimated by NEWHYBRIDS were used to generate $Q$-values according to Berthier et al. (2006). In our study, the $Q$-value represents an overall estimate of the proportion of the genome of an individual being of pure M. lusitanicus ancestry.

An intrinsic issue with Bayesian analyses is that validity of the assumed distribution of prior(s) cannot be assessed statistically; thus, simulations were used for our data set to evaluate the statistical power for correctly identifying the individuals as parentals or hybrids (Nielsen et al. 2006). We used the software HYBRIDLAB 1.0 (Nielsen et al. 2006), which generates multilocus hybrid genotypes based on given parental populations. The parental genotypes consisted of individuals morphologically classified as $M$. duodecimcostatus and M. lusitanicus and assigned to their species cluster $(q>0.95)$ using STRUCTURE. From this pool, we randomly selected 50 individuals from each species to generate 100 genotypes of each parental and hybrid class $\left(F_{1}, F_{2}, F_{1} \times M\right.$. duodecimcostatus, $F_{1} \times M$. lusitanicus). This procedure was replicated 10 times and STRUCTURE was run with $K=2$ on the generated genotypes. The efficiency and accuracy of the assignment of the individuals was calculated as suggested by Vähä \& Primmer (2006), using the threshold values of $0.05,0.10$, 0.20 and 0.30 . The same set of simulated genotypes was used in NEWHYBRIDS for analogous analyses.

\section{Results}

Genetic variation and taxonomic classification based on $m t D N A$

Sequencing of the complete $c y t b$ of 122 individuals yielded 93 different haplotypes defined by 186 polymorphic and 109 parsimony informative sites. We found 42 haplotypes in $54(77 \%)$ sequenced individuals morphologically classified as $M$. duodecimcostatus, and 38 in 52 (73\%) M. lusitanicus, with nucleotide diversities of 0.017 and 0.023 , respectively. Haplotypes were only shared by individuals from the same locality or from geographically close sites (Table 1). GenBank accession numbers are given in Table 1.

Phylogenetic reconstructions showed that mtDNA haplotypes do not segregate overall according to morphological classification of individuals into M. lusitanicus and M. duodecimcostatus (Fig. 2). The topology of the phylogenetic tree is relatively shallow with a most remarkable and well-supported basal split separating the sequences of the two taxa from a previous phylogenetic analysis (Jaarola et al. 2004) as well as the new sequences (net divergence: $3.3 \%$ ). Only six new haplo- 


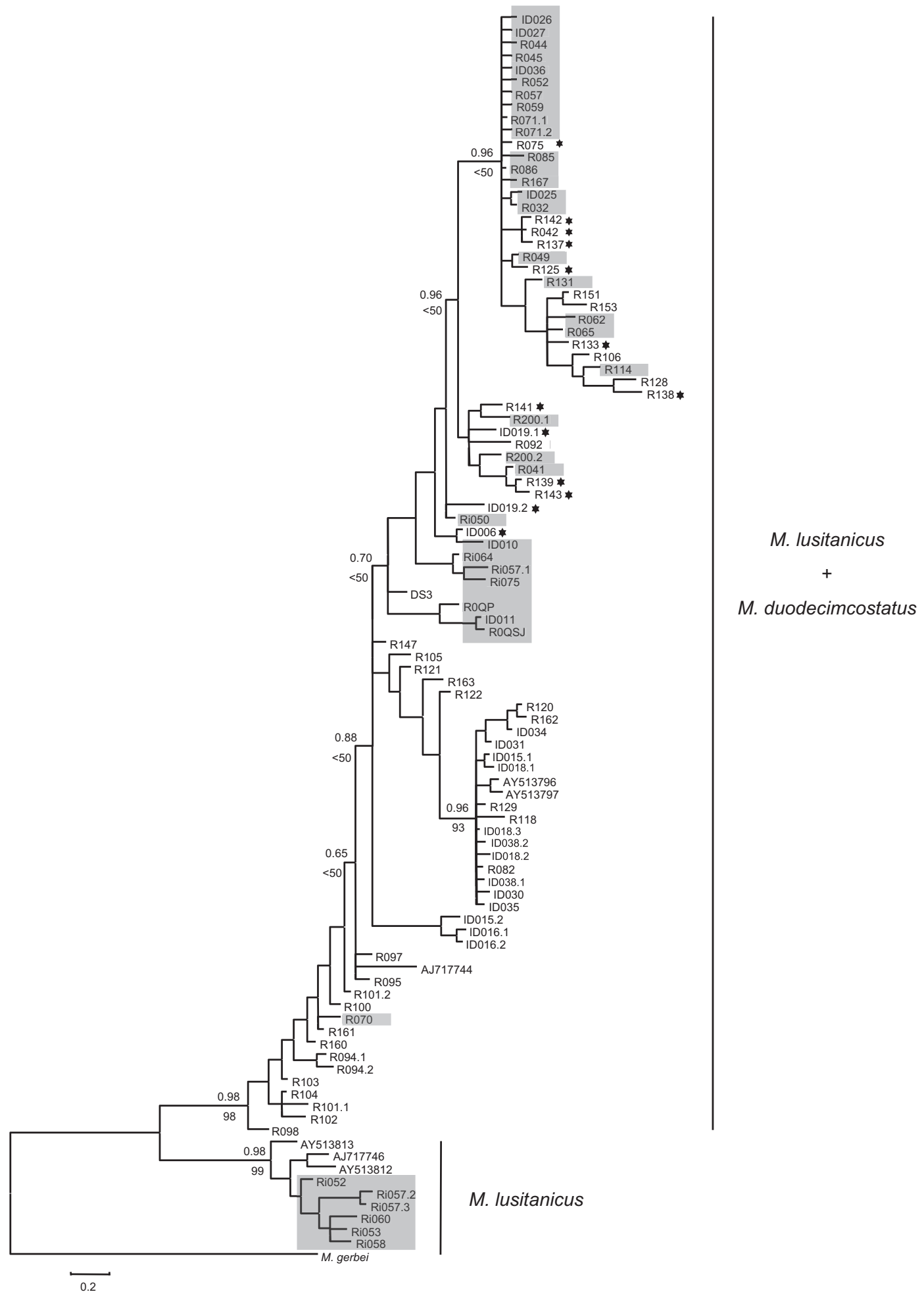

Fig. 2 Reconstruction of phylogenetic relationships of cytb haplotypes from individuals morphologically classified as Microtus lusitanicus or M. duodecimcostatus with M. gerbei as outgroup. Haplotype labels are according to Table 1. Bootstrap values from Neighbour-Joining algorithms and Bayesian posterior probabilities are listed above and below the main nodes, respectively. Morphological identification of individuals from this study is indicated as follows: Microtus sp $(*)$, M. lusitanicus (grey shadow) and M. duodecimcostatus (blank) 
types (Ri052, Ri053, Ri057.2, Ri057.3, Ri058, Ri060) clustered with the M. lusitanicus sequences from Spain and France (locations C, D, E in Fig. 1). The according six individuals were captured at the northernmost sampling sites in Portugal (Table 1). All remaining haplotypes clustered with $M$. duodecimcostatus sequences from France and Portugal (locations A, B, F in Fig. 1), regardless of their morphological classification or of their origin in the allopatric or sympatric parts of the distribution ranges.

\section{Genetic structure and geographical patterns based on nuclear DNA}

Genetic variation at the 13 microsatellite loci was high with a mean number of alleles per locus of 15.7 across all samples, and individual loci showing between three (MAR016) and 34 (AVP-INb) alleles. Morphologically identified $M$. duodecimcostatus $(N=132)$ had a mean of 12.7 alleles (range 3-28) and $M$. lusitanicus $(N=108)$ had on average 13.2 alleles per locus (range 3-28). Mean observed and expected heterozygosity were 0.5 and 0.61 , respectively, for $M$. duodecimcostatus and 0.63 and 0.74 for M. lusitanicus. Considering the distribution of our samples across most of the distribution ranges of the two taxa, the deficit in observed heterozygosity can be explained by the presence of several populations.

Principal component analysis provided overall evidence of two distinct genetic clusters in our nuclear data set largely consistent with the morphological classification of individuals in M. duodecimcostatus and M. lusitanicus. In the analysis of the complete data set including individuals from the allopatric and sympatric parts of the ranges, PCA axis 1 explained $17.8 \%$ of the variability and axis $23.9 \%$ (Fig. 3A). Axis 1 separated genotypes from most morphologically identified M. duodecimcostatus and M. lusitanicus irrespective of their sympatric or allopatric origin. Individuals that were morphologically not assignable to either taxon in the field ( $N=51$; including 18 juveniles or subadults) clustered all with $M$. lusitanicus genotypes. Furthermore, 14 individuals identified as M.duodecimcostatus based on morphology clustered also within the M. lusitanicus group. Given that discrimination between the two taxa in the field is mostly based on size-related traits with partially overlapping distribution, we hypothesized that large individuals of the smaller taxon ( $M$. lusitanicus) might have been wrongly classified as the larger taxon (M. duodecimcostatus) owing to age or geographical variation. A new PCA
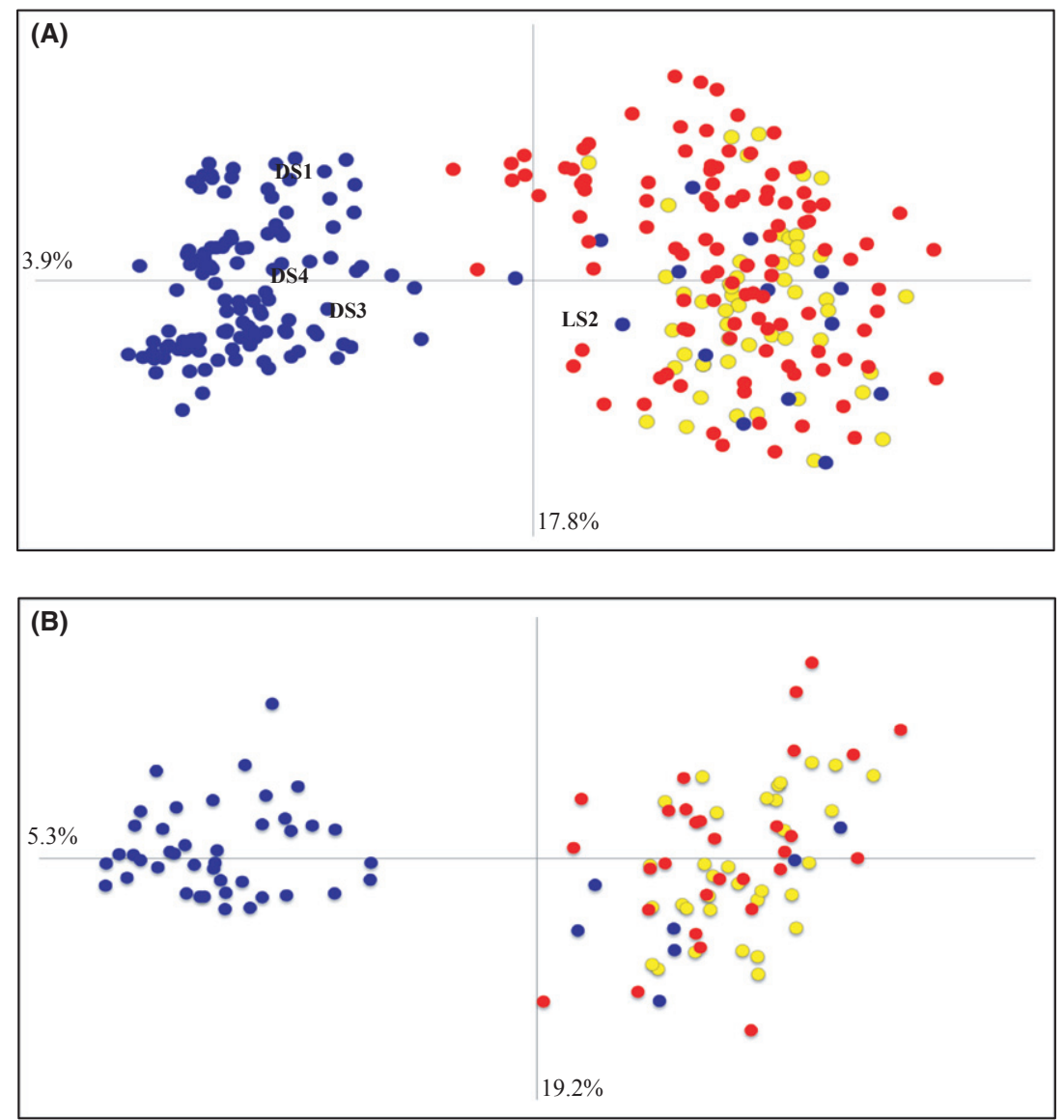

Fig. 3 Principal component analysis (PCA) performed on microsatellite genotypes of morphologically determined Microtus duodecimcostatus (blue), M. lusitanicus (red) and individuals of undetermined species (yellow). Shown are the first two principal component axes (PC1 and PC2) and the variance explained. (A) PCA including all individuals from the allopatric and sympatric parts of the ranges. Individuals from Spain are indicated by their ID number and the corresponding geographical localities in Fig. 1 are as follows: DS1 (110), LS2 (111), DS3 (112) and DS4 (113). (B) PCA including only adult individuals from the sympatric area. 
based only on adult individuals with clear signs of reproductive activity from the sympatric area $(N=112)$ showed that there were still seven individuals that had $M$. duodecimcostatus morphology but genotypes similar to M. lusitanicus (Fig. 3B).

The integration of genetic and spatial information in GENELAND supported the presence of two distinct clusters in nuclear DNA in the sympatric area with a relatively complex geographical distribution (Fig. 4). All posterior distributions peaked at $K=2$ with very little support for other $K$ values. The 10 best runs with $K=2$ converged to a geographical pattern where the two genetic clusters occupy ranges with a complex omega-shaped line of genetic discontinuity, which matches only loosely the distribution of soil types in the region (Fig. 4). All individuals, except one (R087-1) at the borderline, were assigned to one of the two clusters with posterior probabilities exceeding 0.9. This was generally consistent with morphology, but in agreement with PCA results, the 14 individuals classified morphologically as $M$. duodecimcostatus were assigned to the M. lusitanicus population. Morphologically defined M. lusitanicus were found north of the genetic discontinuity line whereas most morphologically defined M. duodecimcostatus were present south of it.

The Evanno et al. (2005) approach for the STRUCTURE analyses strongly suggested two genetic clusters in the sympatric area. All individuals identified as Microtus sp. and $M$. lusitanicus were assigned to cluster I, resulting in an average proportion of membership of $Q=0.994$ and $Q=0.987$, respectively (Fig. S1A, Supporting information).
M. duodecimcostatus were overall assigned to cluster II with $Q_{i}=0.857$. At the individual level, the 14 voles classified morphologically as $M$. duodecimcostatus were assigned to cluster I with $q>0.99$, in agreement with PCA and GENELAND results. After removal of these individuals, the $Q$-value of $M$. duodecimcostatus rose to 0.98 . NEWHYBRIDS showed for 202 of 227 voles posterior probabilities larger than 0.95 for having a pure genotype from one of the two taxa. In agreement with the analyses above, 45 of 47 Microtus sp. were likely M. lusitanicus, and 12 of $14 \mathrm{M}$. duodecimcostatus had posterior probabilities exceeding 0.95 for being pure M. Iusitanicus (Fig. S1B, Supporting information).

Overall, there was profound unidirectional cytonuclear discordance in the data set, which extends north beyond the sympatric area far into the M. lusitanicus range (see Fig. 1). Seventy-six individuals carried $M$. duodecimcostatus mtDNA and M. lusitanicus nuclear DNA, but the reverse combination was not detected. Forty individuals were classified as M. duodecimcostatus for both genomes and six voles were M. lusitanicus for both marker types.

\section{Evidence of recent hybridization in the sympatric area}

Genotype simulations with HYBRIDLAB indicated highest robustness of hybrid identification at $q=0.20$ (overall performance was $96 \%$ for parental individuals and $94 \%$ for hybrids; Fig. S2, Supporting information). At this threshold, the efficiency of assigning simulated individuals with

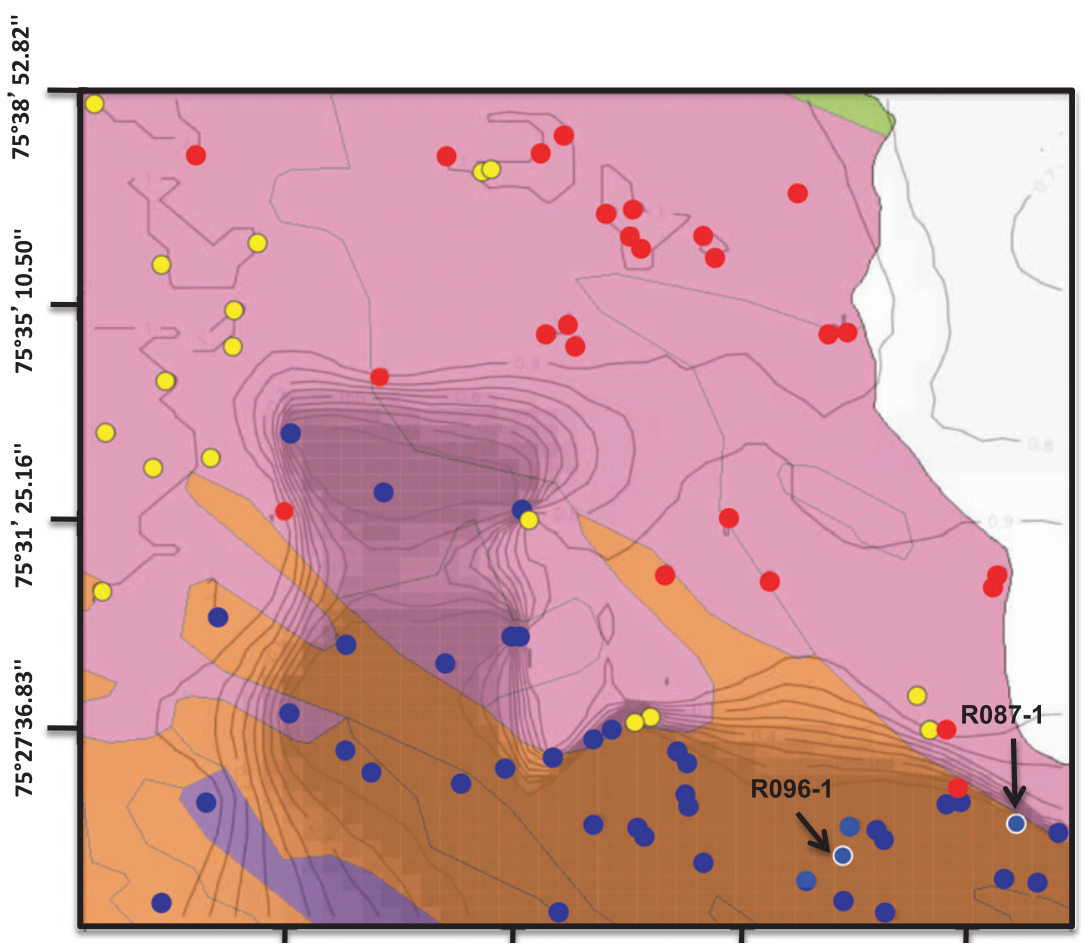

Fig. 4 Map of genetic clustering in the sympatric area of Microtus lusitanicus and M. duodecimcostatus generated by Geneland overlaid on a map showing the types of soil in the study area (pink = cambisol; orange $=$ luvisol; green $=$ leptosol; purple $=$ vertisol). Dots represent sampling sites (see Fig. 1), and colours represent morphological identification as in Fig. 3: Microtus sp. (yellow); M. lusitanicus (red) and $M$. duodecimcostatus (blue). The probability of nucDNA class membership is indicated with brightness: morphologically identified $M$. duodecimcostatus were mostly found in the area covered by the dark-shaded (southern) cluster. The arrows indicate the capture location of the two voles identified as likely hybrids (see text). Note that all individuals shown on this figure harboured M. duodecimcostatuslike mtDNA. 
STRUCTURE was $100 \%$ for pure M. duodecimcostatus $(Q=0.904)$ and $96 \%$ for pure $M$. lusitanicus $(Q=0.928)$ genotypes, and $99 \%$ and $94 \%$ for $F_{1}$ and $F_{2}$, respectively. The proportion of backcross individuals identified as parentals was $47 \%$ in the case of $F_{1} \times M$. duodecimcostatus and $35 \%$ in $F_{1} \times M$. lusitanicus. For NEWHYBRIDS, none of the simulated $M$. duodecimcostatus individuals were assigned to the M. lusitanicus, $F_{1}$ or $F_{2}$ classes, but $21 \%$ appeared as $F_{1} \times M$. duodecimcostatus backcross. Similarly, none of the $M$. lusitanicus were assigned to the $M$. duodecimcostatus, $F_{1}$ and $F_{2}$ classes, but $41 \%$ were assigned to the class $F_{1} \times M$. lusitanicus. Simulated $F_{1}$ and $F_{2}$ individuals were all correctly assigned except for two $F_{2}$, which appeared as a backcross $F_{1} \times M$. duodecimcostatus.

Individual assignments with STRUCTURE and NEWHYBRIDS provided evidence of very limited recent hybridization between $M$. duodecimcostatus and M. lusitanicus. STRUCTURE indicated two individuals as admixed (R087-1: $q=0.607$; R096-1: $q=0.585)$, which were both morphologically determined as $M$.duodecimcostatus and trapped within the range of the southern cluster identified by GENELAND (Fig. 4). NEWHYBRIDS suggested the same two individuals as admixed with overall $Q=0.75$ and $Q=0.5$, respectively, and posterior probabilities lower than 0.5 for being purebred. R087-1 shared its $c y t b$ haplotype with a M. duodecimcostatus (ID034-1) captured within the southern part of the sympatric area. R096-1 had a unique haplotype. NEWHYBRIDS suggested a third individual from the southern part as potential hybrid (R149-4: $Q=0.28$ ), which was assigned a likely $M$.duodecimcostatus by STRUCTURE $(q=0.18)$ and morphology.

\section{Discussion}

The results of this study highlight the importance and necessity of multiple sources of information for resolving evolutionary processes in systems with comparatively low evolutionary divergence and potential interbreeding at different time scales. In the Iberian pine voles analysed here, morphological, ecological, nuclear and mitochondrial data taken each separately provide only incomplete and partially misleading portraits of their geographical distribution, evolutionary divergence and the extent of gene flow among them. The combined analysis resolved evidence of deep and ancient mitochondrial introgression between these pine vole taxa that are otherwise apparently genetically mostly isolated but relatively difficult to classify based on morphology alone.

\section{Cytonuclear discordance}

The comparison of geographic patterns in mtDNA, nucDNA and morphotypes demonstrated extensive cytonuclear discordance in these ecologically divergent Iberian voles. The basal dichotomy in our mtDNA data is consistent with phylogenetic surveys of the Microtus genus in terms of the level of sequence divergence between these lineages and their allopatric distribution in Iberia (Jaarola et al. 2004; Fink et al. 2010). Within these basal clusters, there is relatively high haplotypic variation with strongly localized and nonoverlapping geographic distributions - a feature which is similar to phylogeographic patterns in other European Microtus species (e.g. Jaarola \& Searle 2002; Heckel et al. 2005). However, the phylogeographic patterns in our mtDNA data reflect neither the well-established morphology-based distribution ranges of the two species (e.g. Madureira 1984 studied 1800 specimens across Iberia) nor the profound genetic subdivision detected in nucDNA. In contrast to mtDNA, the nuclear subdivision corresponds largely to the $M$. duodecimcostatus and M. lusitanicus morphotypes and PCA results for the individuals from Spain suggest that this extends over large distances. It is thus most likely that the distribution of mtDNA polymorphisms in these taxa was affected by specific evolutionary processes leading to discordance with the morphological species designation.

Morphologically established taxa may be difficult to distinguish with genetic markers, for example, owing to the incomplete sorting of ancestral polymorphisms or the effects of historical or ongoing gene flow (e.g. Petit \& Excoffier 2009). mtDNA markers are less likely to be affected by incomplete lineage sorting compared with nuclear loci owing to the smaller effective size of mitochondrial loci but the stochasticity of these processes may nevertheless produce inconsistencies with the rest of the genome (Hudson \& Turelli 2003). However, the geographically coherent distribution of the haplotypes belonging to the basal mtDNA clusters and the mixing of morphotypes in only one of them render pure stochasticity unlikely and rather suggest restricted gene flow between the two taxa in the form of introgressive hybridization as the likely cause of incongruence with morphology and nucDNA.

\section{Asymmetric and geographically widespread introgression}

Hybridization beyond the F1 generation may-in principle-lead to the presence of both parental types of mtDNA in hybrids but asymmetric gene flow between closely related species and parapatric evolutionary lineages is indeed relatively common at least in the immediate zone of contact (e.g. Jaarola et al. 1997; Buggs 2007; Plötner et al. 2008; Petit \& Excoffier 2009; Beysard et al. 2012). Our data show that introgression of $M$. duodecimcostatus mtDNA into the range occupied by $M$. lusitanicus extends relatively far beyond the region 
of sympatry. The direction of introgression is consistent with results from limited breeding experiments, which indicated that hybridization is possible under laboratory conditions (Wiking 1976). A detailed characterization of the depth of mtDNA introgression in this system will require a wider coverage of the northern parts of the range of $M$. lusitanicus but it is clear that it extends several dozens or hundreds of kilometres beyond the immediate sympatry or contact zone (see Fig. 1).

The large introgressed territory together with the low dispersal abilities of voles (Hamilton et al. 2005; Schweizer et al. 2007; Santos et al. 2010b; Le Galliard et al. 2012) suggests a relatively old hybridization event between the two taxa with consistent spread of M.duodecimcostatus mtDNA afterwards. This could be explained by either neutral processes or a selective advantage of $M$. duodecimcostatus mtDNA in a M. lusitanicus nuclear background. Selection has also been considered as a force for mtDNA introgression in other organisms (e.g. Melo-Ferreira et al. 2005; Renoult et al. 2009), but there is no direct support of non-neutrality of mtDNA and only very localized evidence from another Microtus species (Fink et al. 2004). In our study, the large diversity of introgressed mtDNA haplotypes in M. lusitanicus argues against a recent selective sweep but very old adaptive processes cannot be excluded. In general, the importance of adaptive mutations in mtDNA in natural populations is still unclear (Ballard \& Melvin 2010).

A selectively neutral alternative scenario for the deep introgression detected here would consist in an invasion of one taxon into the range of the other with considerable interbreeding. Such range expansion processes with gene flow between the invading and the local species may lead to massive introgression of the invaders at neutral genes (Currat et al. 2008). Male-biased dispersal, which is common in Microtus (Hahne et al. 2011; Le Galliard et al. 2012), and limited intra-specific gene flow may cause mtDNA to introgress more than nuclear markers in such invasions (Petit \& Excoffier 2009). To be consistent with our data, this would require $M$. lusitanicus to have invaded the range of $M$. duodecimcostatus. At present, there is no evidence of such a range expansion in this particular system although very limited fossil data suggest their presence in the same locality (Caldeirão Cave near Tomar) slightly north of the current sympatry zone approximately 20-30 000 years ago (Brunet-Lecomte \& Povoas 1993). It is worth noting, however, that the Iberian Peninsula contains a number of independent cases with relatively deep mitochondrial introgression (e.g. Alves et al. 2003; Renoult et al. 2009). A wide range of climates and topographical diversity potentially leading to microrefugia within the Iberian refugium (Gomez \& Lunt 2007) and repeated vegetation changes associated with the glacial cycles certainly provided the necessary conditions for both neutral and adaptive processes conducive to lead to introgression of mtDNA between hybridizing taxa in this region.

\section{Past and present hybridization}

The sharing of a mtDNA lineage between the two pine vole taxa demonstrates ancient hybridization but overall levels of hybridization have been apparently low. Several analytical approaches detected consistently two major genetic clusters in nucDNA in the area of contact between the two morphological taxa where hybridization might actually occur (Figs 3 and 4). The genetic distinctness at this regional scale suggests very limited historical gene flow, which is generally supported by morphological determination, even though the size overlap between the two taxa makes morphology error-prone particularly for large M. lusitanicus. Under relatively stringent conditions, we have evidence of two hybrids among 227 individuals; less stringent criteria might suggest a few additional backcrosses more but reliable statistical distinction from parentals is very difficult for these (Vähä \& Primmer 2006). However, the regional scale of our analyses prevents us from estimating hybridization rates directly. Dedicated sampling of local populations in the direct contact zone of the two taxa will be necessary to determine if current hybridization is actually very rare or whether partial reproductive barriers only prevent gene flow beyond the F1 generation (see e.g. Schilthuizen et al. 2011; Smadja \& Butlin 2011).

The factors maintaining the genetic integrity of the two taxa in the sympatric region are currently unknown, but attempts of experimental crossing indicate the contribution of behavioural mechanisms (i.e. differences in aggression levels; Wiking 1976). Very low sample sizes in these experiments prevent further conclusions, but limited evidence from other Microtus taxa at different stages of speciation suggests that premating and/or postmating mechanisms leading to partial reproductive isolation may evolve relatively quickly in this rapidly radiating rodent genus (Jaarola et al. 1997; Bulatova et al. 2010; Beysard et al. 2012).

It remains unclear how important the role of ecology or habitat preferences is in the maintenance of the general genetic integrity of these pine voles or whether such differences are rather a consequence of competitive exclusion at the local scale. Competitive exclusion in this system would require an advantage of the smaller species $M$. lusitanicus over $M$. duodecimcostatus to be consistent with the invasion scenario for the asymmetrical introgression of mtDNA from above. In our overlay of a soil map with GENELAND results, M. lusitanicus occurs mainly in the cambisol class and $M$. duodecimcostatus in leptosols and luvisols but there are several localities with 
exceptions (Fig. 4). Although these mismatches might be explained by a resolution of the soil map, which is too coarse for representing local habitat conditions or the particular interpolation of likelihoods in GENELAND, it is still consistent with ecological data suggesting that M. duodecimcostatus is able to occupy a wider range of soil types, while M. lusitanicus may not (Santos et al. 2010a,b). However, habitat features like soil thickness and the percentage of plant cover differ also in other regions of the sympatry zone between these pine voles (Borghi et al. 1994), which indicates the importance of ecological factors for the separation of the two taxa.

\section{Conclusion}

The completion of the speciation process is notoriously difficult to determine in nascent species, and the Iberian pine voles studied here exemplify this. Our results show that the current classification as two species is appropriate or not-depending on the species concept favoured (see Mitchell-Jones et al. 1999; Baker \& Bradley 2006). More importantly, however, these two taxa are apparently at a point in the speciation process where genetic and phenotypic differences have established but interbreeding may still occur. We are thus in a position to combine in the future the comparative characterization of their evolutionary history at a large geographical scale with population-based analyses of genome-wide gene flow patterns and experimental approaches to phenotypic divergence and reproductive isolation. Such comprehensive analyses hold very much potential for a deeper understanding of this particular system and the mechanisms behind the ongoing explosive radiation of Arvicoline rodents in general.

\section{Acknowledgements}

We are grateful to Mathias Beysard for helpful suggestions on the manuscript and Isabel Rey from the Museo Nacional de Ciencias Naturales (MNCN), Spain, for providing biological samples. CBS is supported by postdoctoral grant FCT-SFRH/ BPD/26612/2005, Synthesis Grant ES-TAF-5106 and a Research Project FCT-PTDC/BIA-BEC/103729/2008. SMS is supported by $\mathrm{PhD}$ grant PRAXIS/SFRH/BD/21403/2005. GH acknowledges support from the Swiss National Science Foundation grant 31003A_127377/1.

\section{References}

Alves PC, Ferrand N, Suchentrunk F, Harris DJ (2003) Ancient introgression of Lepus timidus mtDNA into L. granatensis and L. europaeus in the Iberian Peninsula. Molecular Phylogenetics and Evolution, 27, 70-80.

Anderson EC, Thompson EA (2002) A model-based method for identifying species hybrids using multilocus genetic data. Genetics, 160, 1217-1229.
Baker RJ, Bradley RD (2006) Speciation in mammals and the genetic species concept. Journal of Mammalogy, 87, 643-662.

Ballard JWO, Melvin RG (2010) Linking the mitochondrial genotype to the organismal phenotype. Molecular Ecology, 19, 1523-1539.

Ballard JWO, Whitlock MC (2004) The incomplete natural history of mitochondria. Molecular Ecology, 13, 729-744.

Berthier P, Excoffier L, Ruedi M (2006) Recurrent replacement of mtDNA and cryptic hybridization between two sibling bat species Myotis myotis and Myotis blythii. Proceedings of the Royal Society B: Biological Sciences, 273, 3101-3109.

Beysard M, Perrin N, Jaarola M, Heckel G, Vogel P (2012) Asymmetric and differential gene introgression at a contact zone between two highly divergent lineages of field voles (Microtus agrestis). Journal of Evolutionary Biology, 25, 400-408.

Borghi CE, Giannoni SM, Martinez-Rica JP (1994) Habitat segregation of three sympatric fossorial rodents in the Spanish Pyrenees. Zeitschrift für Säugetierkunde, 59, 52-57.

Braaker S, Heckel G (2009) Transalpine colonisation and partial phylogeographic erosion by dispersal in the common vole Microtus arvalis. Molecular Ecology, 18, 2518-2531.

Brunet-Lecomte P, Povoas L (1993) Voles (Arvicolidae, Rodentia) from Caldeirão Cave (Tomar, Portugal). Arquivos do Museu Bocage, 24, 409-414.

Brunhoff C, Galbreath KE, Fedorov VB, Cook JA, Jaarola M (2003) Holarctic phylogeography of the root vole (Microtus oeconomus): implications for late Quaternary biogeography of high latitudes. Molecular Ecology, 12, 957-968.

Buggs RJA (2007) Empirical study of hybrid zone movement. Heredity, 99, 301-312.

Bulatova NS, Potapov SG, Lavrenchenko LA (2010) Genomic versus chromosomal polytypy in studies of mitochondrial and nuclear DNA markers in the Microtus arvalis group. Russian Journal of Genetics, 46, 586-594.

Cabrera A (1914) Fauna Ibérica. Mamíferos. Imprenta de Fontanet. Madrid.

Cotilla I, Palomo LJ (2002) Microtus duodecimcostatus (de SelysLongchamps, 1839). In: Atlas de los mamíferos terrestres de España (eds Palomo LJ, Gisbert J), pp. 378-381. Dirección General de Conservación de la Naturaleza, SECEM-SECEM$\mathrm{U}$, Madrid.

Coyne JA, Orr HA (2004) Speciation. Sinauer Associates, Sunderland, Massachusetts.

Currat M, Ruedi M, Petit RJ, Excoffier L (2008) The hidden side of invasions: massive introgression by local genes. Evolution, 62, 1908-1920.

De Selys-Longchamps M (1839) Campagnols inédits. Revue Zoologique par La Société Cuvierienne, 8-9.

Ellerman JR, Morrison-Scott TS (1951) Checklist of Paleartic and Indian Mammals. British Museum (Natural History), London.

Evanno G, Regnaut S, Goudet J (2005) Detecting the number of clusters of individuals using the software STRUCTURE: a simulation study. Molecular Ecology, 14, 2611-2620.

Excoffier L, Laval G, Schneider S (2005) Arlequin ver. 3.0: an integrated software package for population genetics data analysis. Evolutionary Bioinformatics Online, 1, 47-50.

Fink S, Excoffier L, Heckel G (2004) Mitochondrial gene diversity in the common vole Microtus arvalis shaped by historical divergence and local adaptations. Molecular Ecology, 13, 3501-3514. 
Fink S, Excoffier L, Heckel G (2006) Mammalian monogamy is not controlled by a single gene. Proceedings of the National Academy of Sciences of the United States of America, 103, 10956-10960.

Fink S, Excoffier L, Heckel G (2007) High variability and non-neutral evolution in the mammalian avpr1a gene. BMC Evolutionary Biology, 7, e176.

Fink S, Fischer MC, Excoffier L, Heckel G (2010) Genomic scans support repetitive continental colonization events during the rapid radiation of voles (Rodentia: Microtus): the utility of AFLPs versus mitochondrial and nuclear sequence markers. Systematic Biology, 59, 548-572.

Gerbe MZ (1879) Etude comparative de quelques caractères du campagnol incertain. Revue et Magasin de Zoologie $3^{\circ}$ Série, 7, 42-47.

Glaubitz J (2004) CONVERT: a user-friendly program to reformat diploid genotypic data for commonly used population genetic software packages. Molecular Ecology Notes, 4, 309-310.

Gomez A, Lunt DH (2007) Refugia within refugia: patterns of phylogeographic concordance in the Iberian Peninsula. In: Phylogeography of Southern European Refugia. Evolutionary Perspectives on the Origins and Conservation of European Biodiversity (eds Weiss S, Ferrand N), pp. 155-188. Springer, Netherlands.

Good JM, Hird S, Reid N et al. (2008) Ancient hybridization and mitochondrial capture between two species of chipmunks. Molecular Ecology, 17, 1313-1327.

Goudet J (1999) PCAGEN, a computer package which performs Principal Component Analysis (PCA) on gene frequency data. Available from: http://www2.unil.ch/popgen/softwares/pcagen.htm.

Guillot G, Mortier F, Estoup A (2005) Geneland: a computer package for landscape genetics. Molecular Ecology Notes, 5, 712-715.

Hahne J, Jenkins T, Halle S, Heckel G (2011) Establishment success and resulting fitness consequences for vole dispersers. Oikos, 120, 95-105.

Hamilton G, Currat M, Ray N, Heckel G, Beaumont M, Excoffier L. (2005) Bayesian estimation of recent migration rates after a spatial expansion. Genetics, 170, 409-417.

Heckel G, Burri R, Fink S, Desmet J-F, Excoffier L (2005) Genetic structure and colonization processes in European populations of the common vole Microtus arvalis. Evolution, 59, 2231-2242.

Hellborg L, Gunduz I, Jaarola M (2005) Analysis of sex-linked sequences supports a new mammal species in Europe. Molecular Ecology, 14, 2025-2031.

Hudson RR, Turelli M (2003) Stochasticity overrules the "three-times rule": genetic drift, genetic draft, and coalescence times for nuclear loci versus mitochondrial DNA. Evolution, 57, 182-190.

Ishibashi Y, Saitoh T, Abe S, Yoshida MC (1995) Polymorphic microsatellite DNA markers in the grey red-backed vole Clethrionomys rufocanus bedfordiae. Molecular Ecology, 4, 127-128.

Ishibashi Y, Yoshinaga Y, Saitoh T et al. (1999) Polymorphic microsatellite DNA markers in the field vole Microtus montebelli. Molecular Ecology, 8, 163-164.

Jaarola M, Searle JB (2002) Phylogeography of field voles (Microtus agrestis) in Eurasia inferred from mitochondrial DNA sequences. Molecular Ecology, 11, 2613-2621.
Jaarola M, Tegelstrom H, Fredga K (1997) A contact zone with noncoincident clines for sex-specific markers in the fied vole (Microtus agrestis). Evolution, 51, 241-249.

Jaarola M, Martínková N, Gunduz I et al. (2004) Molecular phylogeny of the speciose vole genus Microtus (Arvicolinae, Rodentia) inferred from mitochondrial DNA sequences. Molecular Phylogenetics and Evolution, 33, 647-663.

Jaarola M, Ashford RT, Ratkiewicz M, Brunhoff C, Borkowska A (2007) Isolation and characterization of polymorphic microsatellite loci in the field vole, Microtus agrestis, and their crossutility in the common vole, M. arvalis. Molecular Ecology Notes, 7, 1029-1031.

Le Galliard J-F, Remy A, Ims RA, Lambin X (2012) Patterns and processes of dispersal behaviour in arvicoline rodents. Molecular Ecology, 21, 505-523.

Maan ME, Seehausen O (2011) Ecology, sexual selection and speciation. Ecology Letters, 14, 591-602.

Madureira ML (1981) Discriminant analysis in Portuguese pine voles: Pitymys lusitanicus Gerbe and Pitymys duodecimcostatus de Sélys-Longchamps (Mammalia: Rodentia). Arquivos do Museu Bocage Série A, I, 111-122.

Madureira ML (1984) A biologia de Microtus (Pitymys) duodecimcostatus de Sélys-Longchamps, 1839 e M. (P.) lusitanicus Gerbe, 1879 em Portugal (Arvicolidae, Rodentia): taxonomia, osteologia, ecologia $e$ adaptações. Unpublished PhD Thesis, Department of Animal Biology, Faculty of Sciences, University of Lisbon, Lisbon.

Mallet J, Meyer A, Nosil P, Feder J (2009) Space, sympatry and speciation. Journal of Evolutionary Biology, 22, 2332-2341.

Manoukis NC (2007) FORMATOMATIC: a program for converting diploid allelic data between common formats for population genetic analysis. Molecular Ecology Notes, 7, 592-593.

Melo-Ferreira J, Boursot P, Suchentrunk F, Ferrand N, Alves PC (2005) Invasion from the cold past: extensive introgression of mountain hare (Lepus timidus) mitochondrial DNA into three other hare species in northern Iberia. Molecular Ecology, 14, 2459-2464.

Mira A, Mathias ML (2002) Microtus lusitanicus (Gerbe, 1879). In: Atlas de los mamíferos terrestres de España (eds Palomo LJ, Gisbert J), pp. 378-381. Dirección General de Conservación de la Naturaleza, SECEM-SECEMU, Madrid.

Mitchell-Jones AJ, Amori G, Bogdanowicz W, Krystufek B, Reijnders PJH et al. (1999) The Atlas of European Mammals. T \& AD Poyser, London.

Nei M, Li W-H (1979) Mathematical model for studying genetic variation in terms of restriction endonucleases. Proceedings of the National Academy of Sciences of the United States of America, 76, 5269-5273.

Nielsen EE, Bach LA, Kotlicki P (2006) HYBRIDLAB (Version 1.0): a program for generating simulated hybrids from population samples. Molecular Ecology Notes, 6, 971-973.

Nosil P, Harmon LJ, Seehausen O (2009) Ecological explanations for (incomplete) speciation. Trends in Ecology and Evolution, 24, 145-156.

Paradis E, Guédon G (1993) Demography of a mediterranean microtine: the Mediterranean pine vole, Microtus duodecimcostatus. Oecologia, 95, 47-53.

Petit RJ, Excoffier L (2009) Gene flow and species delimitation. Trends in Ecology and Evolution, 24, 386-393.

Plötner J, Uzzell T, Beerli P, Spolsky C, Ohst T et al. (2008) Widespread unidirectional transfer of mitochondrial DNA: a case in western Palearctic water frogs. Journal of Evolutionary Biology, 21, 668-681. 
Posada D (2008) jModelTest: phylogenetic model averaging. Molecular Biology and Evolution, 25, 1253-1256.

Pritchard JK, Stephens M, Donnelly P (2000) Inference of population structure using multilocus genotype data. Genetics, 155, 945-959.

Renoult JP, Geniez P, Bacquet P, Benoit L, Crochet PA (2009) Morphology and nuclear markers reveal extensive mitochondrial introgressions in the Iberian Wall Lizard species complex. Molecular Ecology, 18, 4298-4315.

Ronquist F, Huelsenbeck JP (2003) MrBayes 3: Bayesian phylogenetic inference under mixed models. Bioinformatics, 19, 1572-1574.

Sambrook J, Fritsch EF, Maniatis T (1989) Molecular Cloning. A Laboratory Manual. Cold Spring Harber Laboratory Press, New York City, New York.

Santos S, Mira A, Mathias ML (2009) Factors influencing largescale distribution of two sister species of pine voles (Microtus lusitanicus and $M$. duodecimcostatus): the importance of spatial autocorrelation. Canadian Journal of Zoology, 87, 1227-1240.

Santos S, Mathias ML, Mira A (2010a) Local coexistence and niche differences between the Lusitanian and Mediterranean pine voles (Microtus lusitanicus and M. duodecimcostatus). Ecological Research, 25, 1019-1031.

Santos SM, Lourenço RF, Mathias ML, Mira AP (2010b) Spatial and temporal ecology of the Lusitanian pine vole (Microtus lusitanicus) in a Mediterranean polyculture. Animal Biology, 60, 209-227.

Santos SM, Mathias ML, Mira AP (2011) The influence of local, landscape and spatial factors on the distribution of the Lusitanian and the Mediterranean pine voles in a Mediterranean landscape. Mammalian Biology, 76, 133-142.

Schilthuizen M, Giesbers MCWG, Beukeboom LW (2011) Haldane's rule in the 21st century. Heredity, 107, 95-102.

Schweizer M, Excoffier L, Heckel G (2007) Fine-scale genetic structure and dispersal patterns in the common vole Microtus arvalis. Molecular Ecology, 16, 2463-2473.

Smadja CM, Butlin RK (2011) A framework for comparing processes of speciation in the presence of gene flow. Molecular Ecology, 20, 5123-5140.

Tamura K, Nei M (1993) Estimation of the number of nucleotide substitutions in the control region of mitochondrial DNA in humans and chimpanzees. Molecular Biology and Evolution, 10, 512-526.

Tamura K, Peterson D, Peterson N, Stecher G, Nei M, Kumar S (2011) MEGA5: molecular evolutionary genetics analysis using maximum likelihood, evolutionary distance, and maximum parsimony methods. Molecular Biology and Evolution, 28, 2731-2739.

Tavaré S, Balding DJ, Griffiths RC, Donnelly P (1997) Inferring coalescence times from DNA sequence data. Genetics, 145, 505-518.

Vähä JPK, Primmer CR (2006) Detecting hybridization between individuals of closely related populations-a simulation study to assess the efficiency of model-based Bayesian methods to detect hybrid individuals. Molecular Ecology, 15, 63-72.

Walser B, Heckel G (2008) Microsatellite markers for the common vole (Microtus arvalis) and their cross-species utility. Conservation Genetics, 9, 479-481.

Wiking VH (1976) Karyologie und Biologie der beiden iberischen Wühlmausarten Pitymys mariae und Pitymys duodecimcostatus. Zoologische Systematik und Evolutionsforschung, 14, 104-129.

C.B.S. research focuses on the use of natural history collections and molecular data to understand the role of past and present environmental changes in affecting evolution of small mammals in the Iberian Peninsula and Mozambique. S.M.S. is specialised in microtine ecology and currently focuses on road barrier effects and functional landscape connectivity for different mammal and bird species. R.M. is interested in the energy demands and contrains of small mammals and the ecological factors regulating their physiological processes. M.M.L. is currently interested in short and long-term adaptation strategies of small mammal species to cope with ever-changing environments. G.H. has broad interests ranging from speciation and colonisation processes over host-pathogen co-evolution, the molecular ecology of dispersal and mating systems to the evolution of behaviorally-active genes.

\section{Data accessibility}

DNA sequences: GenBank accessions JX424119JX424211.

Microsatellite data: DRYAD entry doi:10.5061/dryad. q3ng0.

\section{Supporting information}

Additional Supporting Information may be found in the online version of this article.

Fig. S1 Admixture analyses of observed individuals from the sympatric area of Alto Alentejo, computed by STRUCTURE (A) and NEWHYBRIDS (B).

Fig. S2 The efficiency of detecting parental and F1 individuals simulated by Hybridlab for different STRUCTURE thresholds $q$-values.

Please note: Wiley-Blackwell are not responsible for the content or functionality of any supporting materials supplied by the authors. Any queries (other than missing material) should be directed to the corresponding author for the article. 